\title{
Multiple Scale Processes in Microstructural Evolution: Case Study of Self-Reinforced $\beta-\mathrm{Si}_{3} \mathrm{~N}_{4}$
}

\author{
Paul F. Becher ${ }^{\dagger}$ \\ Corporate Fellow Emeritus, Materials Science and Technology Division, \\ Oak Ridge National Laboratory, Oak Ridge, Tennessee, U.S.A.
}

(Received August 9, 2016; Accepted October 17, 2016)

\begin{abstract}
Microstructural design of ceramics has generally focused on information gathered at the micro- and macro-scales and related this to how specific properties could be improved. Ceramic processing serves as the key to optimizes the final microstructure. However, the advent of nano-scale microstructures and highly advanced characterization tools are forcing us to develop new knowledge of what is occurring not just at the micro-scale but also at the atomic level. Thus we are now beginning to be able to address how microstructure is influenced by events at the atomic scale using atomic scale images and data. Theoreticians have joined us in interpreting the mechanisms involved in the "microstructural" evolution at multiple scales and how this can be used to enhance specific properties of ceramics. The focus here is on delving into the various layers the "microstructure" in order understand how atomic-scale events influence the structure and properties of ceramics.
\end{abstract}

Key words : Silicon nitride, Microstructure, Interfaces, Adsorption

\section{Background}

$\mathrm{T}$ he history of the development of silicon nitride goes back to at least the 1850 , but the advent of the technology of silicon nitride ceramics began in the early 1950s. ${ }^{1)}$ This treatise by Petzow and Herrmann provides an extensive summary of the progress in the processing, phase equilibrium, microstructural development and properties of silicon nitride based ceramics up to the twenty-first century. Credit is due to Gunter Petzow and his colleagues not only for their contributions to our understanding of the behavior of silicon nitride ceramics, but also for providing an international enclave where researchers could jointly conduct research. This served as an important stimulus to advances in not just silicon nitride ceramics but in our understanding of the fundamental processes controlling ceramic microstructures and hence, properties. ${ }^{2)}$

The applications of silicon nitride ceramics, as well as processing techniques, are as varied as the compositions, phases, compositions and microstructures involved. In this paper, we will focus on how the microstructure of self-reinforced $\beta-\mathrm{Si}_{3} \mathrm{~N}_{4}$ evolves and the mechanisms that can control it. Tailoring the microstructure of $\mathrm{Si}_{3} \mathrm{~N}_{4}$ is key to obtaining new and improved properties and hence new applications (e.g., ref. 3). Advances in both atomic resolution microscopy and analytical techniques along with important theoretical

${ }^{\dagger}$ Corresponding author : Paul F. Becher

E-mail : becherpf@comcast.net

Tel : +1-865-805-4365 input have opened up a new view of how microstructures evolve. Microstructural control no longer is based solely on micro- and macro-scale phenomena. Much of what we thought we knew is impacted at what happens at the atomic scale. ${ }^{4)}$ Here we will focus on mechanisms involved in forming self-reinforced microstructures evolve in the presence of rare earth oxide additives.

Self-reinforced silicon nitride ceramics have been of interest for host of applications ranging from automotive and turbine engine components to substrates for power circuits. The development of a self-reinforced microstructure offers the potential for increased fracture strength and decreased sensitivity to flaw size (e.g., rapid increase in fracture resistance (R-curve) as a crack grows in size). ${ }^{5)}$ The presence of larger elongated beta grains, which act as reinforcements similar to that of $\mathrm{SiC}$ whiskers in whisker-reinforced ceramics. ${ }^{6)}$

As discussed in ref. 5, three stages of reinforcement are involved: I. Elastic bridging of the still bonded elongated grains in the immediate crack tip wake, II. Elastic bridging of partially debonded elongated grains further behind the crack tip and finally III. pull-out of debonded elongated grains, Fig. 1. Stage I has the strongest effect on the rise of the R-curve with stage II having a smaller effect, Fig. 1. The region behind the crack tip front where the transition from purely elastic bridging of fully bonded bridging grains to that where partially debonded bridging grains exist affects the slope of the R-curve. But determining the critical crack size where Region I ends and Region II begins is difficult at best. This is because the actual microstructure consists of reinforcing grains which are oriented at various angles to 


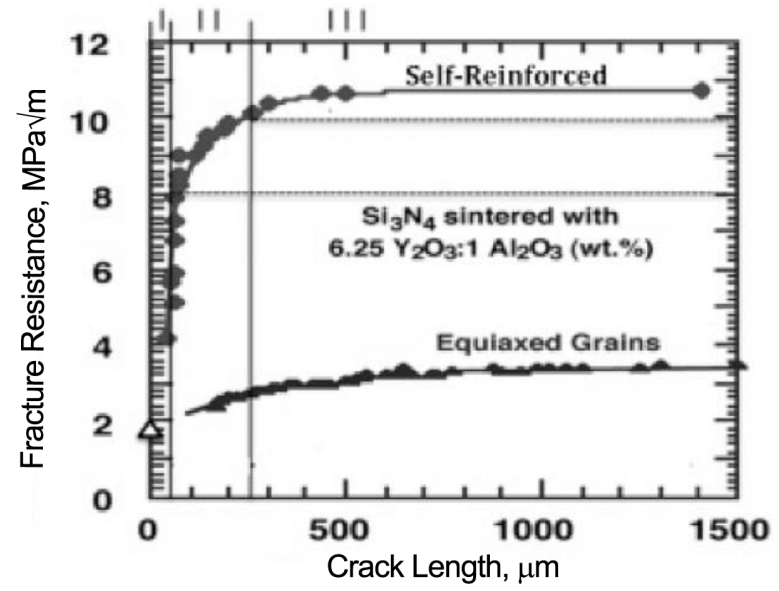

Fig. 1. The introduction of elongated c-axis grains in $\beta-\mathrm{Si}_{3} \mathrm{~N}_{4}$ ceramics can radically increase in the fracture resistance as a small crack grows. This is known as the $\mathrm{R}$-curve effect and an initial rapid rise in the fracture resistance with crack extension affects greater damage resistance to the ceramic. Three regions can be observed in the self-reinforced ceramic: I-elastic bridging of bonded reinforcements, II-elastic bridging with partially debonded reinforcements and IIIpullout of debonded reinforcements.

the crack plane. Thus, a mixture of fully bond and partial debond elastic bridging grains exist in the crack tip wake as soon as the crack begins to grow.

Regardless of the complexity of these transition processes during crack extension, we need insight into the relative ease of debonding of the grains interfaces from the adjacent "amorphous" intergranular film. The method to access grain debonding evolved out of studies of grain growth of $\beta-\mathrm{Si}_{3} \mathrm{~N}_{4}$ grains embedded in SiMe Oxynitrides glasses that contain dispersed elongated $\beta-\mathrm{Si}_{3} \mathrm{~N}_{4}$ grains. ${ }^{7}$

The ease of interfacial debonding is characterized by generating cracks with hardness indentations placed in the glass at given distance from $\beta-\mathrm{Si}_{3} \mathrm{~N}_{4}$ grains. Multiple indentations allow one to generate cracks that intercept grain interfaces at different angles. The data can then be used to determine the angle of intercept $\left(\Theta_{\text {crit }}\right)$ of intercept at which the crack begins to be deflected along the interface between the $\mathrm{Si}_{3} \mathrm{~N}_{4}$ grain and the glass matrix, Fig. 2. Decreasing $\Theta_{\text {crit }}$ values are indicative of a stronger interface. Thus, a decrease $\Theta_{\text {crit }}$ value results in an increase in the number of grains that remain bonded to the matrix in the immediate crack tip wake, see Fig. 2. Note that $\Theta_{\text {crit }}$ decreases when Lu replaces La in the SiMgRE oxynitride glass. Note that the plot in Fig. 2 contains data from ref. 7 plus additional data. ${ }^{8)}$ The fraction of fully bonded elastic bridging grains is reflected in the term $\mathbf{f}$ based on the results in ref. 7 . In SiMgRE oxynitride glasses, the analysis reveals that $\mathrm{Lu}$ promotes the retention of bonded elastically bridging grains in the immediate crack tip wake as compared to the affects of La. Thus one could achieve a faster rising $\mathrm{R}$-Curve $\mathrm{Lu}$ is as the rare eart additive.

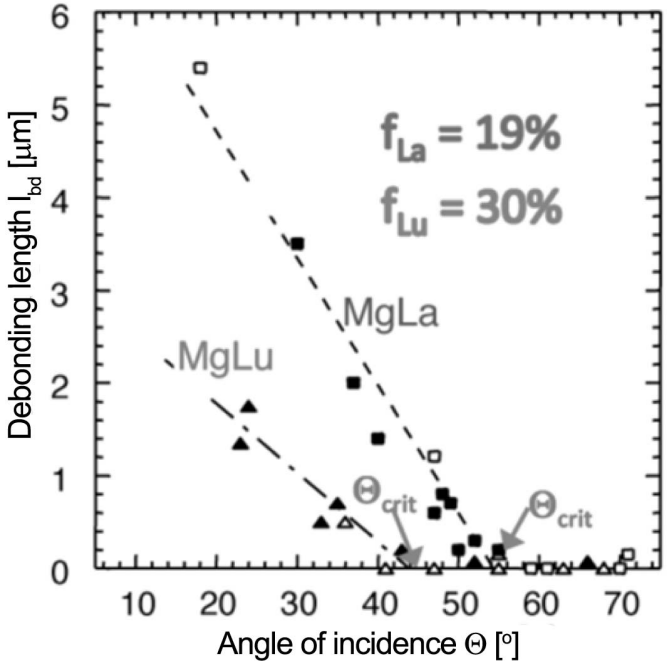

Fig. 2. Debonding of the reinforcing grains control the size of Elastic Bridging I zone. Indentation cracks can be used to assess resistance to debonding at the interfaces.

Aside from room temperature mechanical properties, the tensile creep behavior of silicon nitride ceramics is dominated by microstructure and the additives employed to densify them. Extensive research was conducted to develop $\mathrm{Si}_{3} \mathrm{~N}_{4}$ ceramics that were extremely resistant to creep in air at temperatures similar to those experienced in turbine engines. Early studies revealed that $\mathrm{Mg}$ or $\mathrm{Al}$ additives led to poor creep resistance and that yttria was more promising. Further exploration of larger rare earth additives, revealed that the use of $\mathrm{Lu}_{2} \mathrm{O}_{3}$ as an additive produced a silicon nitride ceramic with a creep resistance rivaling that of superalloys. ${ }^{9)}$

Another potential application of silicon nitride requires, not only good mechanical properties, but also high thermal conductivity. Early theoretical studies ${ }^{10)}$ indicated that silicon nitride could meet the high thermal conductivity; however, this had not been demonstrated in practice until beta silicon nitride ceramics were produced using rare earth additives ${ }^{11)}$ or by introducing a high degree of preferred orientation as studies indicate that thermal conductivity is greatest in $<0001>$ direction. $^{12)}$

\section{2. "Microstructure" Evolution in Self-Reinforced $\beta$-Silicon Nitride Ceramics}

Elongated grains in $\beta-\mathrm{Si}_{3} \mathrm{~N}_{4}$ ceramics are due to the more rapid growth rate in the c-axis direction as compared to that perpendicular to the prism planes. The differences are related to the fact that the "c-axis cap" has a curved/heavily stepped or facetted surface while the prism planes are extremely smooth, Fig. 3. As a result, growth in the c-axis direction is dominated by a fast process that is only limited by diffusion. On the other hand, growth normal to the smooth prism plane is limited by a much slower surface attachment mechanism. 


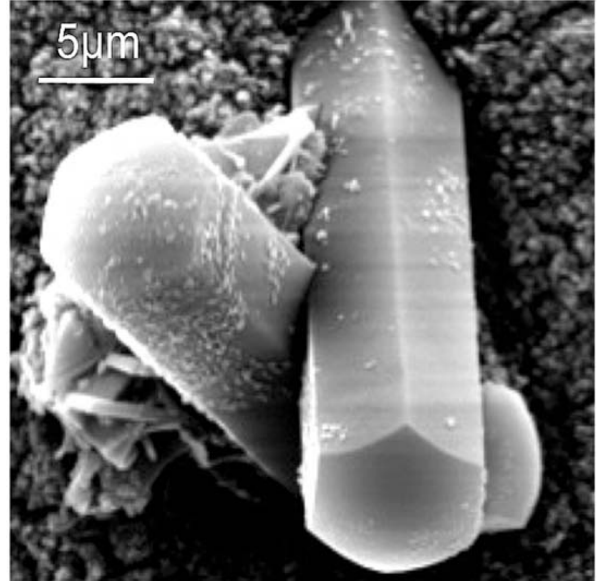

Fig. 3. Large elongated beta grains characteristically smooth prismatic surfaces and curved c-axis caps. (Image courtesy of M. J. Hoffmann, Karlsruhe Institute of Technology).

\subsection{The Impact of Rare Earth Additives on Micro- structure}

Studies of the effect of rare earth additives the microstructures of $\beta-\mathrm{Si}_{3} \mathrm{~N}_{4}$ ceramics revealed that the $\alpha$ to $\beta$ phase transformation temperature decreases as the rare earth size decreases. ${ }^{14,15)}$ Thus grain growth will increase as the size of the rare earth decreases; however, this does not account for the increased anisotropy of grain growth. ${ }^{15-18)}$ There is a general trend for the aspect ratio of the elongated grains increases as the size of the lanthanide and group III ions increase. There correlations between the anisotropic grain growth with other factors (e.g., cationic field strength) have been considered, but these provide no clearer understanding of the role of the rare earths. ${ }^{18)}$

The first real clue came from much earlier analysis of the distribution of rare earths within clusters of beta $\mathrm{Si}_{3} \mathrm{~N}_{4}$ grains embedded in SiRE oxynitride glasses. ${ }^{19)}$ These studies revealed that the concentration of the rare earth within the beta grain clusters was greater than that in the bulk glass. Furthermore, the relative difference in the RE concentration in between the grain clusters versus the bulk glass also increased as the rare earth size decreased. Does this imply that there is a preferred association of the smaller rare earths within the intergranular space between beta grains? This would seem to contradict the observations that the intergranular film thickness increases with increase in the rare earth ion size. ${ }^{20)}$ This would suggest that there would be space for larger rare earths within the intergranular films. At this point, all these observations seem to imply that there is a size effect but it does not explain how the rare earths regulates the anisotropy of grain growth.

Basically, one has to consider that we have overlooked something and that it may be at a level we have not explored. Fortunately for us, advances in electron micros- copy allow us to view atoms and there are some theoreticians who love to determine what atoms are doing, even in ceramics.

\subsection{Mechanisms at the Atomic Level}

At this point, one has to seek out the help of theoreticians who expertise well grounded in materials and microscopists with the skills and equipment to allow one to observe atomic structure working together to aid us in deciphering this dilemma. Fortunately, an international collaboration ${ }^{\text {a) }}$ of evolved to study these and similar issues at the turn of this century.

The approach to understanding the role of the rare earths involved atomic level characterization of beta silicon nitride ceramics containing rare earths. Early studies showed that the rare earths resided at the boundaries of between growth bands produced by thermal cycling of silicon nitride ceramics. ${ }^{1720)}$ Subsequent atomic level observations via Z-contrast scanning transmission electron microscopy were conducted on gas pressure sintered $\mathrm{Si}_{3} \mathrm{~N}_{4}$ ceramics that contained 8 wt.\% $\mathrm{RE}_{2} \mathrm{O}_{3}$ and 2 wt.\% $\mathrm{MgO}$ with $\mathrm{Lu}, \mathrm{Gd}$ and $\mathrm{La}$ as the individual rare earth additivess. ${ }^{21)}$ Here it was revealed that within the intergranular film, the rare earths adsorbed at nitrogen site the on the prism plane surfaces of the silicon nitride grains, e.g., Fig. 4. Moreover, the concentration of rare earth adsorbed sites on the prism plane surfaces also increased with increase in rare earth ion size. Additional supporting observations soon followed..$^{21-26)}$

These findings then reveal that the increasing presence of rare earth elements on the prismatic grain surfaces is a key to hindering diametrical growth of the grains, which increases the grain aspect ratio. The remaining question is

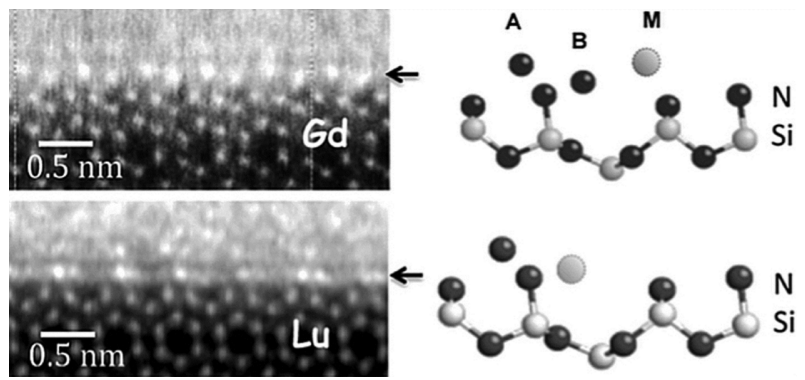

Fig. 4. Adsorption of $\mathrm{RE}$ atoms at the prism plane surface of a $\beta-\mathrm{Si}_{3} \mathrm{~N}_{4}$ grain viewed down the c-axis of the grain and down the prism plane surface. The predicted atomic positions (ball and stick model) are consistent with these observations. Position A is the most stable adsorption site for La, Gd, Lu. Position B is a stable adsorption site for both Gd and La but is a metastable site for Lu. Site M is a metastable site for both $\mathrm{Lu}$ and $\mathrm{Gd}$ but a stable site for La adsorption. ${ }^{27,28)}$

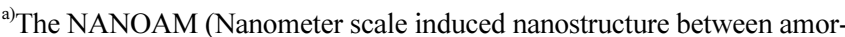
phous layers and crystalline material) program funded by the National Science Foundation and the European Community "Growth" Program. 


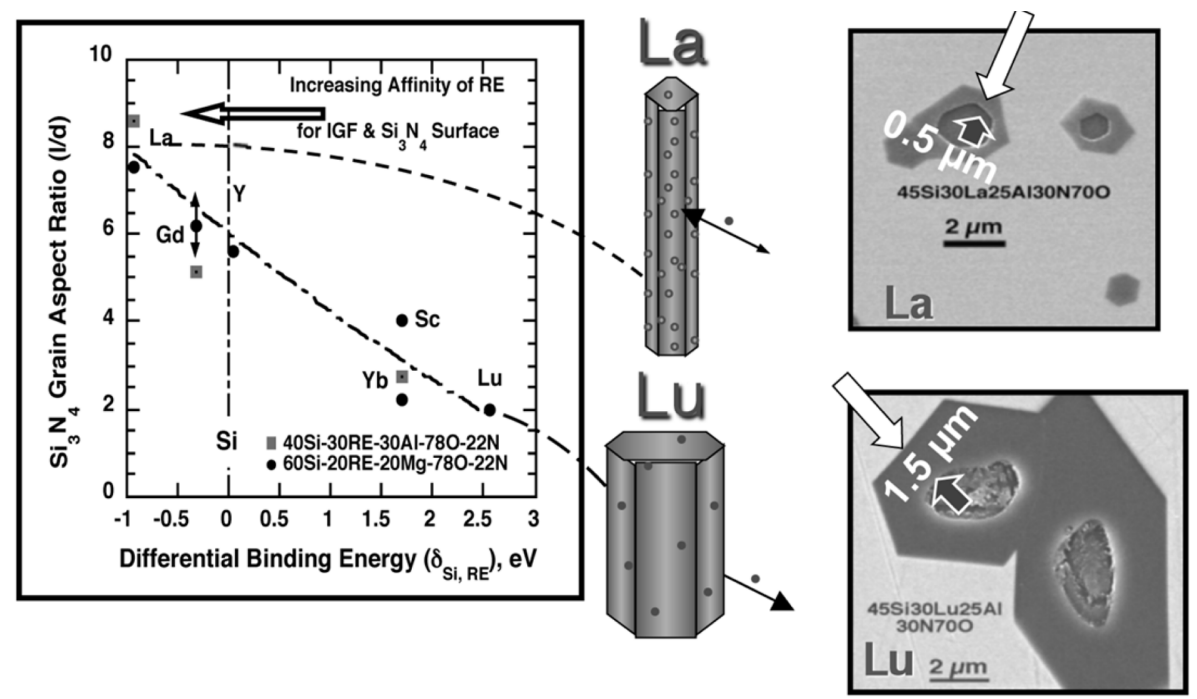

Fig. 5. The calculated Differential Binding Energies for the Rare Earths reveal that the increase in their preference for nitrogen over oxygen as compared to that of silicon is a major factor in the observed increase in the anisotropic grain growth with increase in rare earth size due to the increase in surface adsorption on the prismtic surfaces.

why does this occur? Wherein we turn to the theoreticians to help us understand what is happening. With such help, we might have tools that would guide us and reduce the multiplicity of the efforts it took to get to this point.

The solution involved recognition that the intergranular film between silicon nitride grains and the connected triple points contained both nitrogen and oxygen with a high level of nitrogen at the grain surfaces. Next, one needed to explore if the rare earths had differing preferences for oxygen versus nitrogen and were the preferences greater or less than that of silicon for nitrogen versus oxygen. This concept led to the development of a model based on first-principles analyses of binding energies of both $\mathrm{RE}$ and Si constituents in different $\mathrm{N}$ - and O-based clusters (e.g., in four or six fold coordination) that simulated the local environment pertinent to the interfacial region. ${ }^{27,28)}$ These then assess which anion each RE prefers relative to those same preferences of Si. The resulting calculations are the basis of the Differential Binding Energy $\left(\delta_{\mathrm{Si}, \mathrm{RE}}\right)$ that reveals there is increasing preference of the rare earths for nitrogen sites on the prism plane that is also associated with increase in rare earth ion size. Thus the Differential Binding Energy controls grain growth anisotropy. It reveals that Lu prefers to be associated with oxygen more so than nitrogen as compared to $\mathrm{Si}$ and is less likely to be associated with the grain surfaces. On the other hand, La prefers $\mathrm{N}$ more so than Si does and adsorbs on the prismatic surfaces of the grains. Using these calculations and other first principle calculations, ${ }^{28)}$ one can show that the anisotropic grain growth in $\beta-\mathrm{Si}_{3} \mathrm{~N}_{4}$ controlled by the Differential Binding Energy, Fig. 4 . Hence, it is not the size of the rare earth that dictates the anisotropy of growth. The $\delta_{\mathrm{Si}, \mathrm{RE}}$ calculations also suggest that $\mathrm{Lu}$ has some preference for migrating to triple point regions and one does find more evidence for the presence of RESiONbased phases being present when $\mathrm{Lu}$ is used versus $\mathrm{Gd}$ or
La. Such theoretical contributions continue to add to our understanding of atomic level processes and their impact. The reader is referred to a 2008 review that provides a starting point to review this topic, ${ }^{29)}$ as well as more recent theoretical studies. ${ }^{30,31)}$

\section{Summary}

In the past we considered microstructure to consist of grains, second phases ( e.g, particles, whiskers, precipitates or regions) and grain boundaries that sometimes contain a "film". These grain boundaries and the constituents within them were known to impact properties (e.g., the role of $\mathrm{Mg}$ or Si in behavior of alumina ceramics). Previously, characterization tools evolved to the point that we could characterize micro-structure and image grain boundary regions and gather chemical information that fed into phase and thermal equilibria and densification studies that provided insight into how to process ceramics. Combined with studies of various properties of these ceramics, this provided insight of how to tailor the micro-structure and composition of a ceramic to meet the required performance needed for various applications. Combined with theoretical explanations of events controlling sintering, phase equilibria and properties offer to promote the development of ceramics for new applications in optical, electronic and structural applications.

But many of these new (and future) applications, now require us to understand and control mechanisms/processes at the atomic level. Micro-structure servers as a platform where atomic-level structures and processes are designed and manipulated in order to meet the performance requirements. This is particularly evident in the case of material advances in electronic devices that are beginning to come into service. These advances have been made possible by advances in the theoretical understanding at the atomic 
level and in our ability to image the atomic structure and characteristics of these device materials in order to confirm or revise our understanding of their behavior.

We are now beginning understand that interfaces/interfacial films are critical to our understanding of how microstructure can be impacted, as well as the resultant mechanical and thermal properties. In the present study, theoretical studies revealed that the adsorption of rare earth atoms on nitrogen sites is affected by the affinity of the RE for nitrogen versus oxygen as opposed to that of $\mathrm{Si}$, ie., the Differential Binding Energy. This advancement and additional theoretical studies provide important insights and explain the attachment of the rare earths on the prism plane surfaces of the $\beta-\mathrm{Si}_{3} \mathrm{~N}_{4}$ grains, which influence grain growth. In addition, debonding of the reinforcing grains during crack growth increases as the $\mathrm{RE}$ adsorption decreases. This forms a fundamental basis for exploring how additives influence microstructure including the interfacial characteristics that control mechanical behavior. It also sheds light on the reduction of the oxygen content in $\beta-\mathrm{Si}_{3} \mathrm{~N}_{4}$ grains as the size of the RE additive decreases. Lutetium's preference for oxygen versus that of silicon reduces the oxygen content of the $\beta-\mathrm{Si}_{3} \mathrm{~N}_{4}$ grains. The Differential Binding Energy thus provides a basis for the observed decrease in oxygen content $\beta-\mathrm{Si}_{3} \mathrm{~N}_{4}$ grains as the $\mathrm{RE}$ size decreases. This decrease in oxygen levels within $\beta-\mathrm{Si}_{3} \mathrm{~N}_{4}$ grains has been shown to result in an increase in thermal conductivity. ${ }^{11)}$

One can build upon such studies to rethink how atoms interact within the microstructure especially at interfaces during densification and in resultant properties.

We will need to take advantage of the advances in characterization techniques and develop greater interactions with theoreticians, both those who understand the fundamentals of thermal and mechanical behavior and those who understand how atoms interact. Not everyone can carry out such expansive studies, but we all can learn from those who do. Remember, that behind every micro-structure there are a bunch of atoms whose behavior is important.

\section{Acknowledgments}

The findings summarized here represent the contributions of many colleagues including Gayle Painter, Michael Hoffmann, Naoya Shibata, Klaus van Benthem, H.-T. Lin, Raphaelle L. Satet and S. B. Waters.

\section{REFERENCES}

1. G. Petzow and M. Herrmann, "Silicon Nitride Ceramics," pp. 50-166 in High Performance Non-Oxide Ceramics II, Structure and Bonding, Vol. 102, Springer-Verlag, Berlin, 2002.

2. M. J. Hoffmann and G. Petzow, Tailoring of Mechanical Properties of $\mathrm{Si}_{3} \mathrm{~N}_{4}$ Ceramics; Kluwer Academic Publishers, Dordrecht, 1994.

3. T. Ohji, "Microstructural Control and Mechanical Proper- ties," pp. 657-73 in Handbook of Advanced Ceramics, 2nd Edition, Ed. by S. Somiya, Academic Press, 2013.

4. Grain Boundary Engineering in Ceramics, Ceramic Transaction, Vol. 118, T. Sakuma, L. M. Sheppard and Y. Ikuhara (eds.) American Ceramic Society, Westerville, OH (2000).

5. S. Fünfschilling, T. Fett, M.J. Hoffmann, R. Oberacker, J. Wippler, H. Özcoban, G. A. Schneider, P. F. Becher, and J. J. Kruzic, "Mechanisms of Toughening in Silicon Nitrides: The Role of Crack Bridging and Microstructure," Acta Mater., 59[10] 3978-89 (2011).

6. P. F. Becher, "Microstructural Design of Toughened Ceramics," J. Am. Ceram. Soc., 74 255-69 (1991).

7. J. J. Kruzic, R. L. Satet, M. J. Hoffmann, R. M. Cannon, and R. O. Ritchie, 'The Utility of R-Curves for Understanding Fracture Toughness-Strength Relations in Bridging Ceramics," J. Am. Ceram. Soc., 91 1986-94 (2008).

8. P. F. Becher, additional unpublished data.

9. S. M. Wiederhorn and M. K. Ferber, "Silicon Nitride for Gas Turbines," Curr. Opin. Solid State Mater. Sci., 5 [4] 311-16 (2001).

10. J. S. Haggerty and A. Lightfoot, "Opportunities for Enhancing the Thermal Conductivity of $\mathrm{SiC}$ and $\mathrm{Si}_{3} \mathrm{~N}_{4}$ Ceramics Through Improved Processing," Ceram. Eng. Sci. Proc., 16 [4] 475-87 (1995).

11. (a) M. Kitayama, K. Hirao, A. Tsuge, K. Watari, M. Toriyama, and S. Kanzaki, "Thermal Conductivity of $\beta-\mathrm{Si}_{3} \mathrm{~N}_{4}$ : II, Effect of Lattice Oxygen," J. Am. Ceram. Soc., 83 [8] 1985-92 (2000). (b) M. Kitayama, K. Hirao, M. Toriyama, and S. Kanzaki, "Oxygen Content in $\beta-\mathrm{Si}_{3} \mathrm{~N}_{4}$ Crystal Lattice," J. Am. Ceram. Soc., 82 [11] 3263-65 (1999).

12. K. Watari, B. C. Li, L. Pottier, D. Fournier, and M. Toriyama, "Thermal Conductivity of Beta- $\mathrm{Si}_{3} \mathrm{~N}_{4}$ Single Crystal," Key Eng. Mater., 181-1 239-42 (2000).

13. A. M. Kra“mer, M. J. Hoffmann, and G. Petzow, "Grain Growth Studies of Silicon Nitride Dispersed in an Oxynitride Glass," J. Am. Ceram. Soc., 76 [11] 2778-84 (1993). (b) M. Kra“mer, M. J. Hoffmann, and G. Petzow, "Grain Growth Kinetics of $\mathrm{Si}_{3} \mathrm{~N}_{4}$ During a/b-Transformation," Acta Metall., 41 [10] 2939-47 (1993).

14. M. Kitayama, K. Hirao, M. Toriyama, and S. Kanzaki, "Modeling and Simulation of Grain Growth in $\mathrm{Si}_{3} \mathrm{~N}_{4}$ : The $\alpha-\beta$ Transformation," Acta Mater., 46 [18] 6551-57 (1998).

15. P. F. Becher, G. S. Painter, N. Shibata, S. B. Waters, and H.-T. Lin, "Effects of Rare Earth (RE) Intergranular Adsorption on the Phase Transformation, Microstructure Evolution and Mechanical Properties in Silicon Nitride with $\mathrm{RE}_{2} \mathrm{O}_{3}+\mathrm{MgO}$ Additives: $\mathrm{RE}$ : La, Gd, Lu," J. Am. Ceram. Soc., 91 [7] 2328-36 (2008).

16. A. M. Kitayama, K. Hirao, M. Toriyama, and S. Kanzaki, "Control of b-Si3N4 Crystal Morphology and Its Mechanism (Part II) Effect of Lanthanide Additives," J. Ceram. Soc. Jpn., 107 [11] 995-1000 (1999).

17. R. L. Satet and M. J. Hoffmann, "Grain Growth Anisotropy of $\beta$-Silicon Nitride in Rare-Earth Doped Oxynitride Glasses," J. Eur. Ceram. Soc., 24 3437-45 (2004).

18. P. F. Becher, G. S. Painter, N. Shibata, R. L. Satet, M. J. Hoffmann and S. J. Pennycook, "Influenced of Additives on Anisotropic Grain Growth in Silicon Nitride Ceramics," 
Mater. Sci. Eng. A, 422 85-91 (2006).

19. M. J. Hoffmann, H. Gu, and R. M. Cannon, "Influence of the Interfacial Properties on the Development and Properties of Silicon Nitride Ceramics"; pp. 65-74 in MRS Symposium Proceedings, Vol. 585-Interfacial Engineering for Optimized Properties II, C. B. Carter, E. L. Hall, C. L. Briant, and S. Nutt (editors).MRS, Warrendale, PA, 2000.

20. C. -M. Wang, X. Pan, M. J. Hoffmann, R. M. Cannon and M. Ruhle, "Grain Boundary Films in Rare-Earth-GlassBonded-Based Silicon Nitride,” J. Am. Ceram. Soc., 79[3] 788-92 (1996).

21. N. Shibata, S. J. Pennycook, T. R. Gosnell, G. S. Painter, W. A. Shelton, and P. F. Becher, "Observation of Rare Earth Segregation in Silicon Nitride Ceramics at SubNanometer Dimensions," Nature, 428730-33 (2004).

22. G. B. Winkelman, C. Dwyer, T.S. Hudson, D. NguygenManh, M. Doblinger, R. L. Satet, M. J. Hoffmann and D. J. H. Cockayne, "Three Dimensional Organization of RareEarth Atoms at Grain Boundaries in Silicon Nitride," Appl. Phys. Lett., 87061911 1-3 (2005).

23. N. Shibata, G. S. Painter, R. L. Satet, M. J. Hoffmann, S. J. Pennycook, and P. F. Becher, "Rare Earth Adsorption at Intergranular Interfaces in Silicon Nitride Ceramics: SubNanometer Observations and Theory," Phys. Rev. B, 72 140101 R-1 to -4 (2005).

24. C. Dwyer, A. Ziegler, N. Shibata, G. B. Winkelman, R. L. Satet, M. J. Hoffmann, M. K. Cinibulk, P. F. Becher, G. S. Painter, N. D. Browning, D. J. H. Cockayne, P. O. Ritchie, and S. J. Pennycook, "Interfacial Structure in Silicon
Nitride Sintered with Lanthanide Oxides," J. Mater. Sci., 41[14] 4405-12 (2006).

25. N. Shibata, G. S. Painter, P. F. Becher, and S. J. Pennycook, "Atomic Ordering at an Amorphous /Crystal Interface," Appl. Phys. Lttrs, 89 051908-1 to -3 (2006).

26. K. van Benthem, G. S. Painter F. W. Averill' S. J. Pennycook, and P. F. Becher, "Experimental Probe of Adsorbate Binding Energies at Internal Crystalline/Amorphous Interfaces," Appl. Phys. Lett., 92 163110-1 to -3 (2008).

27. G. S. Painter, P. F. Becher, W. A. Shelton, R. L. Satet and M. J. Hoffmann, "Differential Binding Model: Effects of Rare-Earths on $\beta-\mathrm{Si}_{3} \mathrm{~N}_{4}$ Grain Growth and Microstructure," Phys. Rev. B, 70144108 (2004).

28. G. S. Painter, F. W. Averill, P. F. Becher, N. Shibata, K. van Benthem, and S. J. Pennycook, "First Principles Study of Rare Earth Adsorption at $\beta-\mathrm{S}_{\mathrm{i} 3} \mathrm{~N}_{4}$ Interfaces," Phys. Rev. $B, 78$ 214206-1 to -9 (2008).

29. G. S. Painter and P. F. Becher, Microstructural Design of Ceramics: Theory and Experiment. pp. 233-95 in Ceramic Science and Technology, Vol. 1, Structures, R. Riedel and IW. Chen (eds.) Wiley-VCHf Verlag Gmbh \& Co., 2008.

30. Y. Jiang, Y. Ma, and S. H. Garofalini, "Role of Oxygen on the Interfacial Adsorption Sites of $\mathrm{Lu}$ and $\mathrm{La}$ in $\beta-\mathrm{Si}_{3} \mathrm{~N}_{4}$," Acta Mater., 66 284-92 (2014).

31. Y. Wei, H. Wang, X. Lu, J. Wen, M. Niu, X. Fana, and S. Jia, "Effects of Rare Earth Adsorption on Electronic Structure and Optical Properties in $\beta-\mathrm{Si}_{3} \mathrm{~N}_{4}$ Ceramics from First Principles," RSC Adv., 4 53570-74 (2014). 